\title{
Characterization of the non-functional Fas ligand of gld mice
}

\author{
Michael Hahne, Manuel C. Peitsch², Martin Irmler, Michael Schröter, Bente Lowin, \\ Marga Rousseau, Claude Bron, Toufic Renno', Lars French ${ }^{3}$ and Jürg Tschopp \\ Institute of Biochemistry, University of Lausanne and ${ }^{1}$ Ludwig Institute for Cancer Research, BIL Research \\ Center, Chemin des Boveresses 155, $\mathrm{CH}-1066$ Epalinges, Switzerland \\ ${ }^{2}$ Glaxo Institute for Molecular Biology, Chemın des Aulx 14, CH-1228 Plan-les-Ouates, Switzerland \\ ${ }^{3}$ Division of Dermatology, Geneva University Hospital, $\mathrm{CH}-1211$ Geneva 14, Switzerland
}

Keywords: activity, Fas, gld, structure

\begin{abstract}
Mlce homozygous for elther the gld or Ipr mutation develop autolmmune diseases and progresslve lymphadenopathy. The Ipr mutation ls characterized by the absence of functional Fas, whereas gld mice exhlbit an Inactive FasL due to a point mutation proximal to the extracellular C-terminus. The structural repercussions of this amino acid substltution remain unknown. Here we report that FasL Is expressed at similar levels on the surface of activated $T$ lymphocytes from g/d and wild-type mice. Using a polyclonal anti-FasL antlbody, indistingulshable amounts of a $40 \mathrm{kDa}$ proteln are detected in both gld and wild-type splenocytes. The molecular model of FasL, based on the known structure of TNF- $\alpha$, predicts that the Phe $\rightarrow$ Leu gld mutation ls located at the protomer interface which is close to the FasR interaction slte. We conclude that the gld mutation allows normal FasL biosynthesis, surface expression and oligomerization, but induces structural alterations to the Fas binding region leading to the phenotyplc changes observed.
\end{abstract}

\section{Introduction}

FasL is a member of the type II membrane protein superfamily consisting of TNF- $\alpha$ and $-\beta$ (lymphotoxin- $\alpha$ ), lymphotoxin- $\beta$, CD27L, CD30L, CD40L and 4-1BB (1). Despite the diversity of the biological actıvities elicited by these ligands, most of them are known to induce cellular differentiation or proliferation with two exceptions. FasL and, under some circumstances, TNF are responsible for rapid induction of apoptosis of receptor-bearing cells $(2,3)$.

The importance of a functional Fas-Fas ligand (FasL) system is illustrated by the phenotype of lpr (lymphoproliferation)and gld (generalized disease) mutant mice. MLR mice homozygous for lpr or gld develop a progressive autoimmune disorder, resembling systemic lupus erythematosis in human (4). These mice also suffer from a large accumulation of nonmalignant $\mathrm{CD4}^{-} \mathrm{CD}^{-} \mathrm{T}$ cells in the spleen and in lymph nodes. Genetic analysis indicated that the gld phenotype results from a mutation in FasL $(5,6)$. The $1 p r$ mutation has been correlated with a defect in Fas (7).

The Fas system unquestionably plays a crucial role in the deletion of autoimmune cells. Fas-mediated elimination occurs in the periphery, since both negative and positive selection in the thymus proceed normally in $g / d$ (or $\mid \rho r)$ animals $(8,9)$.

Fas also plays an important role in $\mathrm{T}$ cell cytotoxicity.
Cytolytic T cells use two major cytolytic pathways, one based on perforin-granzymes and one dependent on FasL (10-13). Cytotoxic $T$ cells derived from perforin knock-out mice have considerable killing activity left (14) which is attributable to Fas (10-12). In turn, perforin-containing gld cytotoxic T cells still kill tumor cells, but with reduced efficiency (10).

FasL in g/d/gld mice displays no killing activity upon stimulation with phorbol ester (PMA) and calcium ionophore (ionomycin) $(5,6)$, in spite of normal mRNA levels present $(5,6)$, Moreover, activated g/d $\mathrm{T}$ cells fail to interact with a FasR.Fc hybrid protein $(6,15)$. This functional loss is a result of a single point mutation changing Phe 273 to Leu proximal to the extracellular C-terminus of this type II membrane protein $(5,6)$. In the present study we report on the structural implications of this fatal single amino acid replacement.

\section{Methods}

Expression of bacterial recombinant FasL

cDNA coding for the extracellular domain of FasL was amplified from $1 \mathrm{ng}$ mouse FasL CDNA (GenBank accession no. MMU10984) using the following primers: primer 1, 5'-TTC 
GCT CGA GAA CTG GCA GAA CTC CGT GAG-3'; primer 2, 5'-AAG GAT CCT AGC TGA CCT GTT GGA CCT TGC-3'. The amplified product was cloned into the pCRIl vector using the AT cloning kit (Invitrogen, Heidelberg, Germany) and subsequently subcloned into the page-KG expression vector (kindly provided by $\operatorname{Dr} A$. Quest at our institute) at the EcoRI site. The glutathione-S-transferase (GST)-FasL fusion proteIn was expressed in bacteria upon induction with IPTG.

\section{Antibody production}

A peptide spanning amino acids $196-220$ of the mouse Fas ligand (RGQSCNNQPLNHKVYMRNSKYPEDL), synthesized using the multiple antigen technology (16), was used as antigen. Spleen cells of an immunized rat were fused to NF1 mouse myeloma cells and hybridoma cells secreting peptide specific IgG were selected. Two clones, $\mathrm{H} 11$ and A11, were further analyzed. The same peptide construct was also injected into rabbits for polyclonal antibody production. The antiserum (PE62) was affinity purified on FasL peptıde coupled to $\mathrm{CNBr}$-Sepharose (Pharmacia, Zürich, Switzerland).

\section{Splenocytes and their activation}

B6. gld mice were purchased from Jackson Laboratories (Bar Harbor, ME). Splenocytes were isolated from 6-week-old mice and freed from red blood cells by $10 \mathrm{~min}$ incubation in an ice cold buffer containing $13 \mathrm{mM}$ sodium bicarbonate, $156 \mathrm{mM}$ ammonium chloride and $127 \mu \mathrm{M}$ EDTA, and then resuspended in complete medium. Cells were cultured for $4 \mathrm{~h}$ at $\sim 1 \times 10^{7}$ cells/ml in either the presence or the absence of PMA $(5 \mathrm{ng} /$ $\mathrm{ml}$ ) and ionomycin (500 $\mathrm{ng} / \mathrm{ml}$ ) (Sigma, Buchs, Switzerland).

\section{Flow cytometry}

Analysis was performed on a FACScan cytometer (Becton Dickinson, Mountain View, CA) using the Lysys II software Cells were stained with the anti-FasL antibody PE52 followed by donkey anti-rabbit coupled to fluorescein (Dianova, Hamburg, Germany) and the PE-labeled mAb H 129.19 for L3T3/CD4 and 53-6.7 for Ly-2/CD8 staining (Boehringer, Mannheim, Germany).

\section{SDS-PAGE, Western blot and native electrophoresis}

Splenocytes were washed in ice cold PBS and then boiled in sample buffer for $5 \mathrm{~min}$. Cellular proteins of $\sim 2 \times 10^{6}$ splenocytes per lane were electrophoretically separated on a $10 \%$ polyacrylamide gel in the presence of SDS under nonreducing conditions (17) and subsequently transferred to nitrocellulose. Immunoblot analysis was conducted using plain supernatant of the $\mathrm{mAb} \mathrm{H} 11$ and $\mathrm{A} 11$, and $50 \mu \mathrm{g} / \mathrm{ml}$ of affinity-purified PE62 antibody. First antibodies were detected using anti-peroxidase-conjugated donkey anti-rat and antirabbit antibodies (Dianova, Hamburg. Germany) followed by a chemiluminescence reaction using the ECL system (Amersham, Bucks, UK).

For native electrophoresis the Phast separation system of Pharmacia (Zürich, Switzerland) was employed. Approximately $10^{7}$ splenocytes were lysed in $50 \mu$ lysis buffer (100 $\mathrm{mM} \mathrm{NaCl}, 1 \% \mathrm{NP}-40$ in $50 \mathrm{mM}$ Tris, pH 8.0) containing $1 \mathrm{mM}$ PMSF. Cell lysate $(1 \mu t)$ was applied per lane and the proteins were electrophoretically separated on 4-15\% gradient gels and analyzed by immunoblot analysis as described above. Complement $\mathrm{C} 8$ and $\mathrm{C} 9$ components were used as molecular weight standards.

\section{Results}

\section{Production of FasL specific antibodies}

Polyclonal and monoclonal antibodies were generated against a peptide corresponding to residues $196-220$ of the mouse FasL, predicted to lay on the loop forming the outer tip of the ligand (see below). Affinity-purified polyclonal antiserum (PE62) and two independent mAb (H11 and A11) were used throughout this study. To confirm that these anti-peptide antibodies specifically recognize FasL, the reactivity of the antibodies was tested against the recombinant extracellular domain of FasL. As shown in Fig. 1, both the monoclonal and polyclonal antibodies recognized bacterial lysates containing the GST-FasL fusion protein in Western blots, whereas no band was detectable in lysates transfected with the expression vector containing FasL insert in the inverse orientation. Flow cytometric analysis showed reactivity of the polyclonal antibody PE62 with the native ligand on the cell surface (Fig. 2), while the use of the mAb was restricted to the analysis of denatured protein in Western blots .

\section{Expression of FasL in T lymphocytes of wild-type and gld mutant mice}

FasL MRNA has been detected in activated splenocytes $(3,6)$. Flow cytometric analysis of activated $T$ lymphocytes derived from spleens indeed showed high expression of FasL (Fig. 2). The $\mathrm{CD}^{+}$and the $\mathrm{CD} 8^{+}$subsets showed equally intense FasL staining (data not shown). FasL expression was critically dependent on lymphocyte activation. Only cells that had been previously treated with PMA/ionomycin were positive, while marginal staining of T lymphocytes was observed with nonactivated $T$ cells. Interestingly, only a subpopulation of activated $T$ lymphocytes was FasL positive. Approximately $70 \%$

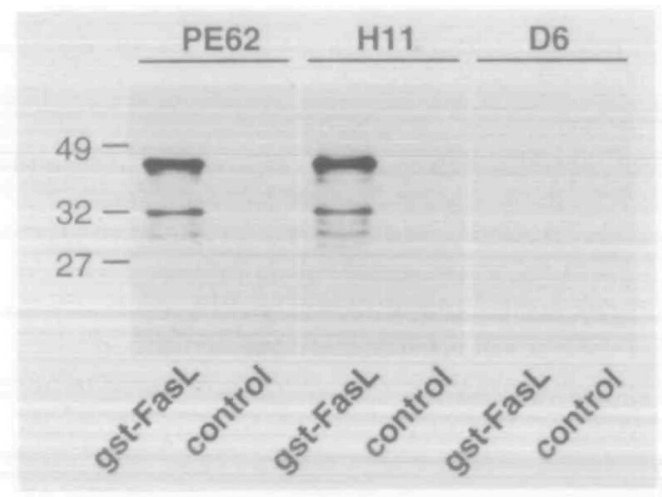

Flg. 1. Characterization of anti-mouse FasL antibodies. Western blot analysis of a bacterial lysate contanning recombinant mouse FasLGST fusion protein ( $46 \mathrm{kDa}$ ) using the affinity-purified PE62 rabbit polycional antibody to FasL or rat monoclonal anti-mFasL H11. The low molecular weight bands most likely correspond to degradation products. Bacterial lysate expressing GST alone served as a negative controt. The D6 mAb antibody detects the peptide 62 in ELISA, but does not react with the recombinant FasL (control lanes). 
remained FasL low. We are currently investigating the phenotype of the FasL positive lymphocyte subpopulation in greater detail.

The relative surface expression of FasL on splenic lymphocytes isolated from wild-type B6 mice with that from g/d B6 mice was compared Previously, Ramsdell (15) showed that the FasR.Fc hybrid protein detected the ligand only on wildtype lymphocytes, whereas the gld $\mathrm{T}$ lymphocytes were negative. Using FasL specific antibodies, however, staining on PMA/ionomycin treated gld T lymphocytes was comparable to that of wild-type $T$ lymphocytes (Fig. 2). Only 30\% of activated gld T lymphocytes expressed high levels of FasL.

This was confirmed by Western blot analysis An equal quantity of protein and an identical size was found in extracts from activated $T$ lymphocytes of wild-type and of $g / d$ origin (Fig. 3). FasL exhibited a molecular weight of $\sim 40 \mathrm{kDa}$, in agreement with the molecular weight of post-transiationally modified FasL in transfected COS cells (18).

\section{Structure of the gld-FasL}

The inability of the FasR.FC hybrid protein to detect $g / d$-FasL points to structural dissimilarities in the Fas binding region of the ligand. Other members of the TNF family have been shown to be active only as trimers and not as monomers $(19,20)$. Similarly, FasL, although present on the surface, could show impaired dimer or trimer formation on the surface of gld T cells. This would be compatible with the observed

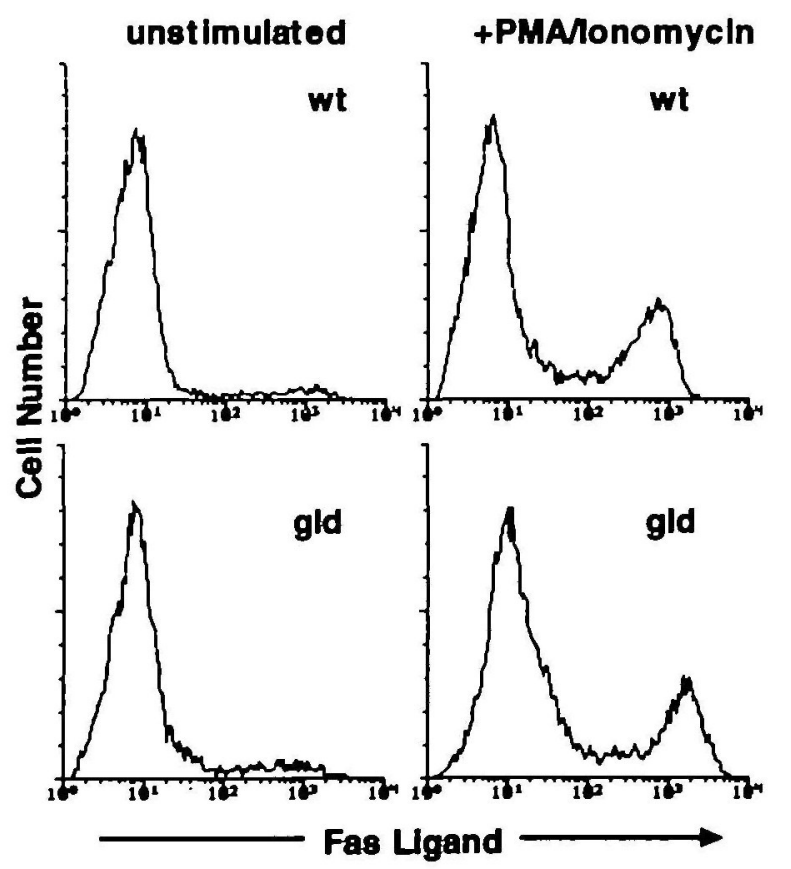

Fig. 2. Expression of FasL on wild-type and gld tymphocytes. FACS analysis of cell surface FasL expression on unstimulated (left panels) and PMAllonomycin $(4 \mathrm{~h})$ stimulated (right panels) $\mathrm{CD} 4^{+}$or $\mathrm{CD}^{+}$ splenocytes of C57BL/6J (B6) (A) or B6-gld origin (B). The flow cytometric profiles show the combined stanning of $\mathrm{CD4}^{+}$and $\mathrm{CD} 8^{+}$ splenocytes stained with the anti-FasL polyclonal antibody PE62. Unrelated antibody control is identical with the profiles of unstimulated splenocytes (upper left panel) difference of FasL surface expression, which differs depending on whether a FasL antibody or the FasR.Fc hybrid protein is used as tool for detection. Whereas the antibody most likely detects multimers and monomers, the receptor.Fc hybrids are known to interact only with multimeric ligands with high affinity.

This hypothesis was supported by the spatial localization of FasL Phe273 to Leu mutation. Although the level of sequence identity between the individual members of the TNF superfamily does not exceed $35 \%$, their three-dimensional structures are expected to be very similar as observed for TNF- $\alpha$ and $-\beta$ for which $X$-ray structures are available. Both factors crystallize in the trimeric form and are detected as such in solution (20-22). Knowledge-based protein modeling of FasL was therefore performed (23). Figure 4(A and $B$ ) shows the predicted three-dimensional structure of the presumptive FasL trimer. The trimer interface is largely dominated by hydrophobic resıdues which are well conserved throughout the TNF family (23). In the g/d mutation the bulky aromatic side chain of Phe273, which is part of the subunit interface, is replaced by the shorter leucine (Fig. 5A). Phe273 is positioned at the center of a $12 \AA$ sphere where several of the best conserved residues of the TNF family are clustered (V144, A145, H146, L158, W160, Y190, V193, G244, A245, F247, F273, G274), although they are quite distant in the sequence. This suggests an important functional role for this particular region. Based on our model of murine FasL, Phe273 (located on strand $\mathrm{H}$ ) interacts mainly with Ala245 (on strand F) of the adjacent subunit (Figs 4 and 5 ). It is responsible for $\sim 50 \AA^{2}$ of the hydrophobic contact surface between individual protomers. The $g / d-F a s L$ model predicts that the contribution of amino acid 273 is reduced by $>20 \AA^{2}$ when replaced by a leucine. This would in turn result in a decrease of hydrophobic interactions between the subunits and suggest that either trimer formation of FasL itself is impaired or that local distortions of the polypeptide backbone occur in the gld mutation. As in the gld mutation, this position is occupied by shorter hydrophobic resıdues, i.e. Isoleucine and valine, in human and mouse CD $30 \mathrm{~L}$ respectively (Fig. $5 \mathrm{~A}$ and $\mathrm{B}$ ). The molecular model of the CD30L (23) shows that the consequent difference

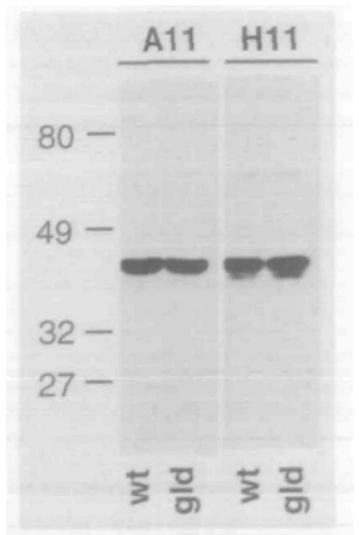

Flg. 3. FasL in splenocytes. Western blot analysis of PMAVionomycin (4 h) stimulated wild-type and gld splenocytes. FasL-detecting antibodies were $\mathrm{H} 11$ and $\mathrm{A} 11$. No staining is seen with an irrelevant mAb (data not shown). 
in subunit contact surface is, however, compensated by CD30L:Leu199 which corresponds to FasL:Ala245 (Fig. 5B).

\section{Oligomerization of FasL}

To determine if there is a failure of trimerization of the $g / d$ FasL, Western blot analysis was performed with the native FasL-recognizing polyclonal PE62 antibody. This antibody normally detected at least three bands under non-reducing conditions, the lowest of $40 \mathrm{kDa}$ co-migrating with that detected by the mAb (Fig. 6A). The two larger bands had apparent molecular weights of $\sim 75$ and $105 \mathrm{kDa}$ respectively. Their molecular masses correlate with the predicted mass of FasL dimers and trimers, and most likely reflect non-dissociated oligomeric forms of the ligand.
To obtain additional information with respect to the aggregation state of FasL in the presence of non-denaturing detergents, activated splenocytes were disrupted with the mild detergent NP-40. The detergent extract was separated by native gradient gel electrophoresis. Subsequent immunoblot analysis revealed multiple FasL-antibody reactive bands. The lowest one had an apparent molecular size of $\sim 200 \mathrm{kDa}$, but two additional FasL antibody-reactive species with apparent molecular masses of $\sim 400$ and $600 \mathrm{kDa}$ were detected. These absolute values have to be interpreted with caution, since NP-40 forms large micellar structures. However, they correspond to dimeric and trimeric forms of the ligand. Importantly, the pattern of these bands was similar in PMA/ionomycin activated splenocytes of wild-type and gld origin.

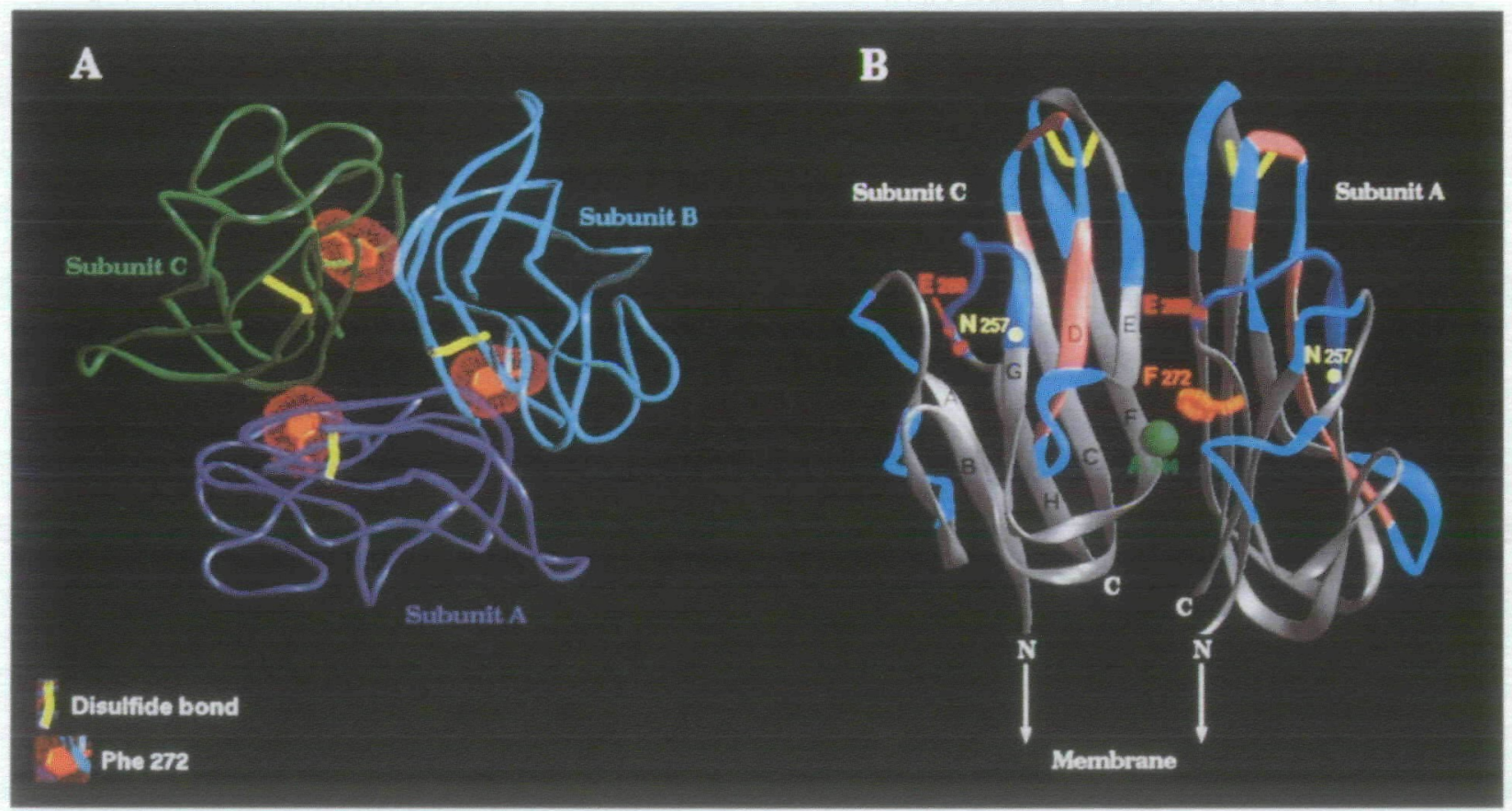

Fig. 4. Molecular model of the murine FasL. Ribbons representation of the murine FasL. In the top view (A), all three subunits, their disulfide bonds and Phe273 mutated in gld-FasL are represented, while in the side view (B) only the subunits $A$ and $C$ are shown for clarity. The receptor-binding loops are depicted in blue (darker blue for the loop linking the $G$ and $H$ strands) while the sequence corresponding to peptide 62 is colored in pink. The green sphere represents the side chain of Ala245 (see Fig. 5A), which is in contact with Phe273 (orange side chain). The residues at the beginning and end of the receptor-binding GH loop are indicated with light yellow and red circles. The $\mathrm{N}$ and C-terminal ends of the extracellular FasL sequence which displays homology to the TNF molecule are indicated with white letters, and the $\beta$-strands are identified by black letters on the $\mathrm{C}$ subunit.

A

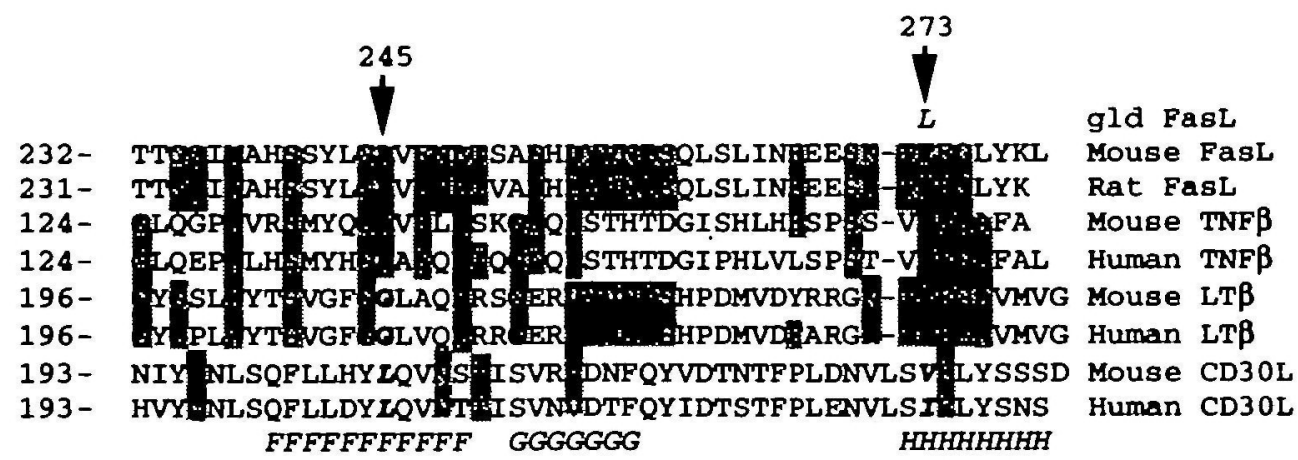



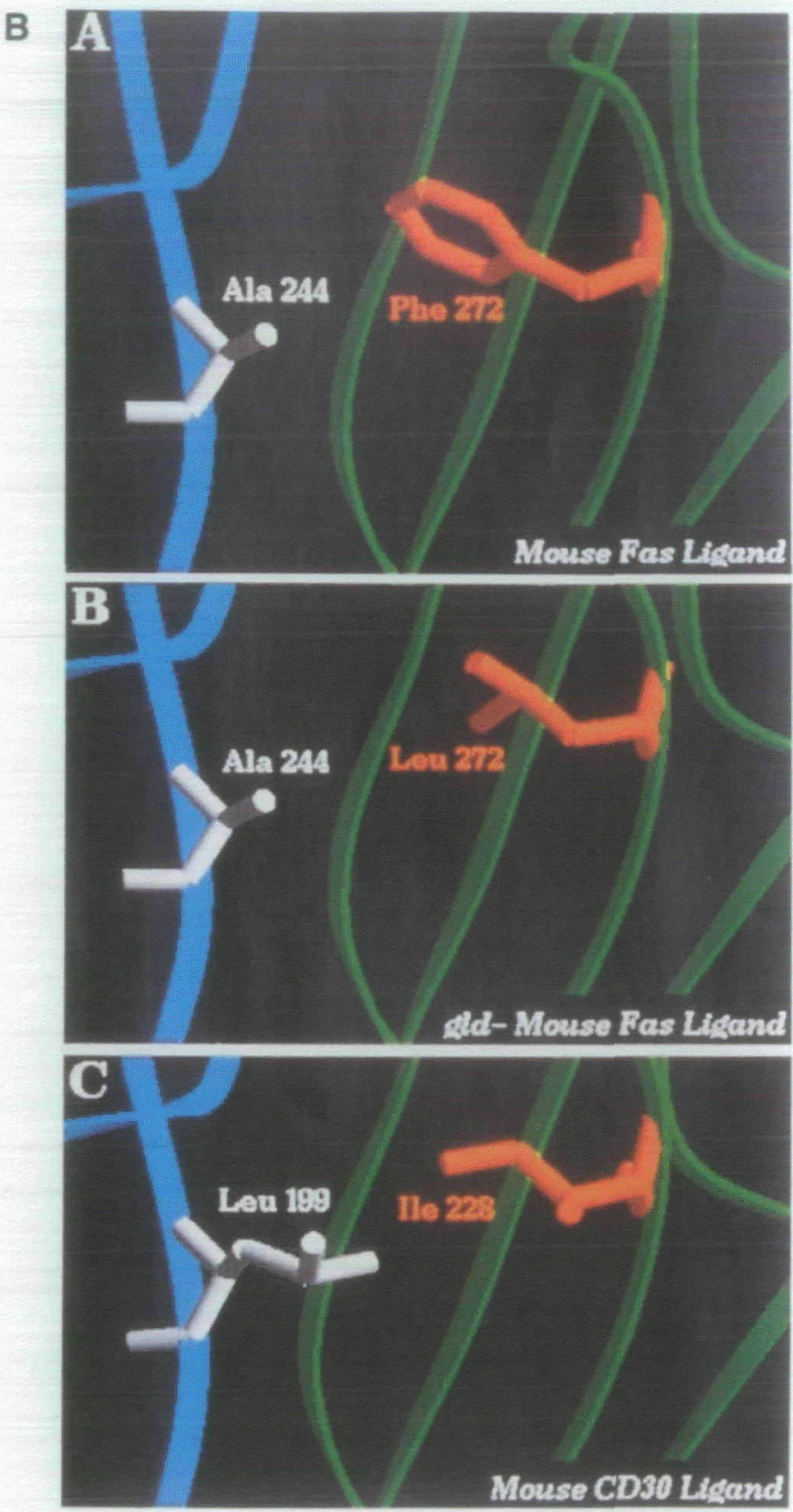

Fig. 5. The interface of the gld-FasL trimer. (A) Multiple amino acid sequence alignment of TNF superfamily members that are most similar to FasL ( $>22 \%$ overall identity), i.e. TNF- $\beta$, lymphotoxin- $\beta$ (LTB) and CD30L. Only the C-terminal region of FasL is shown. Residues identical in $50 \%$ of the sequences are indicated with a shaded background, while those involved in interface formation in the gld mutation are labeled in bold lace and by arrows. The $\beta$ strands are indicated in italics. (B) Representation of a section of the interface between the $A$ (green) and $C$ (blue) subunits of $(A)$ mouse FasL, (B) mouse gld-FasL and (C) human CD30L. The side chains of FasL:Phe273 and FasL.Ala245 are shown in orange and white respectively. The corresponding residues of murine CD30L are shown in the lower panet. The space left empty by the replacement of Phe by $l l e 228$ in $\mathrm{CD} 30 \mathrm{~L}$ is filled by the compensatory replacement of $\mathrm{Ala}$ by Leu199. In gld-FasL, the mutation of Phe273 to Leu is not compensated by the replacement of Ala244 by a larger hydrophobic residue, leaving a large empty space in the structure. To fill this cavity in the trimer structure, gld-FasL may undergo a distortion with dramatic effect on its FasR-binding activity.

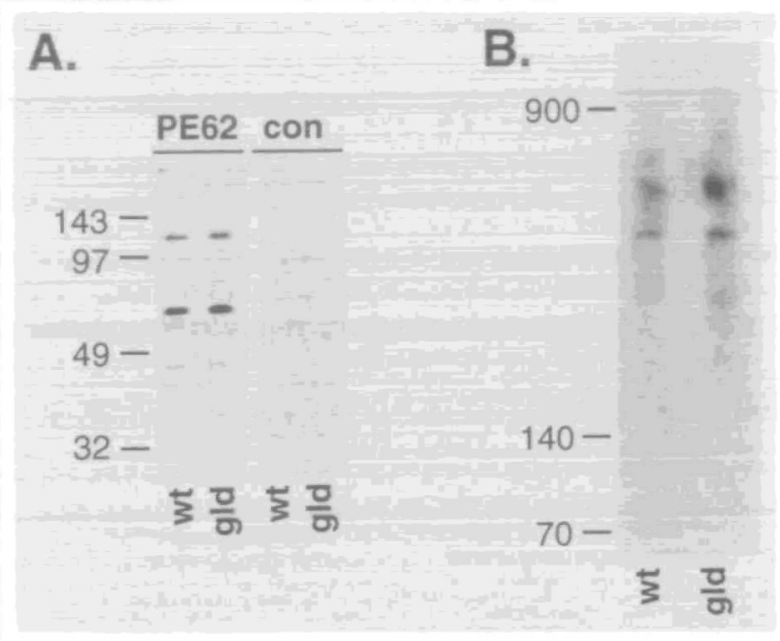

Fig. 6. Olıgomer formation by FasL. (A) Western blot analysis of PMA Ionomycin activated splenocytes using the polyclonal affinity-purified PE62 antibody In the control lanes (con), the first antibody (PE62) was left out during the incubations Negative results were also obtained with irrelevant rabbit IgG. (B) Separation of splenocyte proteins by native gel electrophoresis. FasL antigen was detected by Western blot analysis using the PE62 antibody.

\section{Discussion}

Our results show that the single amino acid change in the gld mutant FasL allows correct post-translational modification and sorting of the ligand to the cellular surface. Furthermore, both the g/d- and wild-type FasL seem to form SDS-resistant oligomers. As shown for soluble members of this ligand family (24), the membrane-associated form of FasL may require surface dimerization or trimerization to display functional activity. There are antibodies to Fas which have ligand-like activities and induce apoptosis in Fas-bearing cells. The two original antibodies which have led to the discovery of Fas (Apo-1) are aggregating antibodies, i.e. of either the $\lg M$ or IgG3 subtype $(25,26)$. $F\left(a b^{\prime}\right)_{2}$ fragments alone are inactive (27). Thus, it is very likely that FasL homotrimer formation is required to induce Fas aggregation and signal transduction.

In the context that the apparent aggregation state of the $g / d-$ and wild-type FasL does not differ in vitro, we favor the conclusion that the gld-FasL's inability to interact with soluble Fas dimers (FasR.FC) and to transmit the signal via Fas results from a local distortion in FasL-FasR interaction site. Closer examination of the structure shown in Fig. $4(\mathrm{~A})$ shows that the critical Phe273 is part of a loop involved in FasR contact (23). This loop links the strands $\mathrm{G}$ and $\mathrm{H}$ (the $\mathrm{GH}$ loop) and ends only four residues before Phe273. The replacement of Phe273 by a leucine most likely alters the structure of strand $\mathrm{H}$ in the FasL trimer. It may then be that the modified structure of strand $\mathrm{H}$ changes the conformation of the $\mathrm{GH}$ loop giving rise to a FasL with impaired FasR-binding activity.

Several mutations in the TNF family leading to distinct phenotypes have been reported. CD40L mutants were discovered in connection with the $X$-linked hyper-IgM syndrome (28). The spatial mapping of human CD40L mutants discovered in connection with the $X$-linked hyper-lgM syndrome (summarized in 28) show that several of the reported point 
mutations probably affect the folding of individual subunits or the interaction with the receptor (23). Two mutations, however, $A 123 \rightarrow E$ and $G 227 \rightarrow V$, are also found at the subunit interface. Interestingly, these two amino acids are located in the same three dimensional region as FasL:Phe273 (12 $\AA$ sphere around Phe273) and correspond to two of the highly conserved residues throughout the TNF family Although more polar subunit interactions (CD40L:Ser256 instead of FasL:Phe273) replace the very hydrophobic ones in the other members of the TNF family, mutations in this region of CD4OL lead to ligands with impaired receptor-binding function as evidenced by the appearance of the X-linked hyper-lgM syndrome in patients bearing such mutations (28). These mutations may lead to similar effects on the conformation of the $\mathrm{GH}$ loop (one of the receptor-binding loops) as in FasL and thus explain the lack of functionality of these mutants. In contrast to CD40L, no mutation affecting FasL activity has been described in humans to date. The pathological consequences of such a mutation, as seen in the gld mouse, may be too profound to allow its occurrence.

\section{Acknowledgements}

The authors gratefully acknowledge the technical assistance of H. Hasler, S. Hertig, T. Bornand and P Allegrini The helpful comments and suggestions of H. R. MacDonald and C. Kamel are also gratefully acknowledged. This work was supported by grants of the Swiss National Science Foundation

\section{Abbreviations}

FasL

GST

$$
\begin{aligned}
& \text { Fas ligand } \\
& \text { glutathione-S-transferase }
\end{aligned}
$$

\section{References}

1 Smith, C. A., Farrah, T. and Goodwin, R. G. 1994. The TNFreceptor superfamily of cellular and viral proteins: activation, costimulation, and death. Cell 76:959

2 Aggarwal, B. B. and Eessaul, T. E. 1987. Human tumor necrosis factor and lymphotoxin: their structural and functional similarities In Tumor Nocrosis Factor, p. 297. Alan R. Liss, New York.

3 Suda, T, Takahashi, T, Golstein, P. and Nagata, S. 1993. Molecular cloning and expression of the Fas ligand, a novel member of the tumor necrosis factor family. Cell 75:1169.

4 Cohen, P. L. and Eisenberg, R. A. 1991. Lpr and glot. single gene models for of systemic autoimmunity and lymphoproliferative disease. Annu. Rev. Immunol. 9:243.

5 Takahashi, T., Tanaka, M., Brannan, C. I, Jenkins, N. A. Copeland, N. G., Suda, T. and Nagata, S. 1994 Generalized lymphoproliferative disease in mice, caused by a point mutation in the Fas ligend. Cell 76:969.

6 Lynch, D. H, Watson, L. M., Alderson, M. R., Baum, P. R., Miller, R. E., Tough, T. W., Gibson, M., Davis-Smıth, T., Smith, C. A., Hunter, G., Bhat, D., Din, W. Goodwin, R. G. and Seldin, M. F 1994. The mouse Fas-ligand gene is mutated in gld mice and is part of a TNF family gene cluster. Immunity 1:131.

7 Watanabe-Fukunaga, R., Brannan, C. I., Itoh, N., Yonehara, S. Copeland, N. G., Jenkins, N. A. and Nagata, S. 1992. The cDNA structure, expression, and chromosomal assignment of the mouse Fas antigen. J. Immunol. 148:1274

8 Singer, G. G. and Abbas, A. K. 1994. The Fas antigen is involved in peripheral but not thymic deletion of $T$ lymphocytes in $T$ cell receptor transgenic mice. Immunity 1:365.

9 Sidman, C. L., Marshall, J. D and von Boehmer, H. 1992. Transgenic $T$ cell receptor interactions in the lymphoproliferative and autoimunne syndromes of $l p r$ and gld mutant mice. Eur. J. Immunol. 146:3340

10 Lowin, B., Hahne, M., Mattmann, C. and Tschopp, J. 1994. Cytolytic T-cell cytotoxicity is mediated through perforin and Fas Iytic pathways. Nature 370.650 .

11 Kojima, H., Shinohara, N., Hanaoka, S., Someya-Shirota, Y., Takagaki, Y., Ohno, $H$., Saito, T., Katayama, T., Yagita, $H$. Okumura, K., Shınkai, Y., Alt, F. W., Masutzawa, A., Yonehara, S. and Takayama, $\mathrm{H}$ 1994. Two distinct pathways of specific killing revealed by perforin mutant cytotoxic T cells Immunity 1:357

12 Kagi, D, Vignaux, F., Ledermann, B., Burki, K., Depraetere, V., Nagata, S., Hengartner, H. and Golsteın, P. 1994. Fas and perforın pathways as major mechanisms of T cell-mediated cytotoxicity. Science 265:528

13 Heusel, J. W., Wesselschmidt, R. L., Shresta, S, Russell, J. H. and Ley, T. J. 1994. Cytotoxic lymphocytes require granzyme B for the rapid induction of DNA fragmentation and apoptosis in allogeneıc target cells. Cell 76:977

14 Lown, B. Beermann, F. Schmidt, A. and Tschopp, J. 1994. A null mutation in the perforin gene impairs cytohytic T lymphocyteand NK-mediated cytotoxicity. Proc. Natl Acad. Sci. USA 9111151 .

15 Ramsdell, F., Seaman, M. S., Miller, R. E., Tough, T. W. Alderson, M. R and Lynch, D H 1994. gld/gld mice are unable to express a functional ligand for Fas Eur $J$ Immunot 24.928.

16 Francis, M. J., Hastings, G. Z , Brown, F. McDermed, J., Lu, Y. A and Tam, J P 1991. Immunological evaluation of the multiple antigen peptide (MAP) system using the major immunogenic site of foot-and-mouth disease virus Immunology 73:249.

17 Laemmli, U. K 1970 Cleavage of structural proteins during the assembly of the head of Bacteriophage T4. Nature 227:680.

18 Suda, T. and Nagata, S. 1994 Purification and characterization of the Fas-ligand that induces apoptosis J Exp. Med 179.873.

19 Smith, $R$ A and Baglioni, C. 1987. The active form of tumor necrosis factor is a trımer. J. Biol. Chem. 262.6951.

20 Eck, M. J., Ultsch, M., Rinderknecht, E., de, V A. M. and Sprang. S. R. 1992 The structure of human lymphotoxin (tumor necrosis factor-beta) at 1.9-A resolution. J. Biol. Chem. 267:2119

21 Loetscher, H., Gentz, R., Zulauf, M., Lustig, A., Tabuchi, H., Schlaeger, E. J., Brockhaus, M , Gallati, H., Manneberg, M. and Lesslauer, W 1991 Recombinant 55-kDa tumor necrosis factor (TNF) receptor. Stoichiometry of binding to TNF alpha and TNF beta and inhıbition of TNF activity. J. Biol. Chem. 266:18324.

22 Jones, E. Y., Stuart, D I. and Walker, N. P. 1989. Structure of tumour necrosis factor. Nature 338:225.

23 Peitsch, M. C. and Tschopp, J. 1995. Comperative molecular modelling of the Fas-ligand and other members of the TNF family Mol. Immunol. in press.

24 Smith, R. A. and Baglioni, C 1989. Multimeric structure of the tumor necrosis factor receptor of HeLa cells. J. Biol. Chem. 264.14646.

25 Yonehara, S., Ishii, A. and Yonehara, M. 1989. A cell-killing monoclonal antibody (anti-Fas) to a cell surface antigen codownregulated with the receptor of tumor necrosis factor. J. Exp. Mod. 169:1747.

26 Trauth, B C. Klas, C. Peters, A. M. Matzku, S., Moller, P. Falk, W. and Krammer, P. H. 1989. Monoclonal antibody-mediated tumor regression by induction of apoptosis. Science 245:301.

27 Dhein, J., Daniel, P. T., Trauth, B. C., Oehm, A., Moller, P. and Krammer, P. H. 1992. Induction of apoptosis by monoclonal antibody anti-APO-1 class switch variants is dependent on crossInking of APO-1 cell surface antigens. J. Immunol. 149:3166.

28 Callard, R. E., Armitage, R. J., Fanslow, W. C. and Spriggs, M. K 1993. CD40 ligand and its role in X-linked hyper-IgM syndrome Immunol. Today 14:559. 